\title{
MÉTODOS DE PURIFICAÇÃO DA ÁGUA PARA LABORATÓRIOS
}

Caio Pestana Barbosa Lorenzo ${ }^{1}$, Daniele Cristine Raimundo ${ }^{2}$, Arnaldo Rocha $^{3}$, Márcia Cristina Menão ${ }^{*}$.

${ }^{1}$ Biólogo. São Paulo-Brasil

${ }^{2}$ Professora da Universidade Metropolitana de Santos (UNIMES) - Santos - Brasil

${ }^{3}$ Professor do Centro Universitário das Faculdades Metropolitanas Unidas - São Paulo - Brasil

$4^{*}$ Professora do Centro Universitário das Faculdades Metropolitanas Unidas (FMU) e da Universidade Paulista (UNIP) - São Paulo - Brasil (marcrismenao@gmail.com)

Recebido em: 22/09/2018 - Aprovado em: 23/11/2018 - Publicado em: 03/12/2018 DOI: 10.18677/EnciBio 2018B88

A água é uma substância essencial para a sobrevivência dos organismos, ocorrendo naturalmente no planeta numa composição que favorece a vida. Entretanto, quando se trata de água para procedimentos laboratoriais, nem a água natural nem a potável tratada são adequadas. Para estas aplicações é necessário que esta seja purificada, a fim de remover as impurezas, como microrganismos e seus subprodutos, matéria orgânica e inorgânica, íons e partículas, que possam interferir nos procedimentos que se deseja realizar. Para tanto, são utilizados métodos físicos, químicos e biológicos de purificação, como destilação, filtração, micro e ultrafiltração, osmose reversa, deionização, eletrodeionização, adsorção e oxidação ultravioleta, a fim de transformar aquela água comum em uma reagente. Para que sejam atingidos os padrões mínimos de qualidade previstos em normas como a ISO 3696 e a CLSI GP40-A4-AMD, é necessária a combinação de duas ou mais destas técnicas, além de correto manuseio e manutenção dos equipamentos de purificação e análises sistemáticas da água reagente, de forma a garantir sua qualidade e adequabilidade para o uso desejado. Assim, a destilação e a eletrodiálise são técnicas pouco utilizadas nos laboratórios em razão de serem processos demorados e apresentarem fraca relação custo benefício, respectivamente, enquanto filtração, osmose reversa, deionização, adsorção e oxidação ultravioleta são amplamente utilizados, normalmente em conjunto, por serem processos mais eficazes, eficientes e de mais fácil operação.

PALAVRAS- CHAVE: água reagente, laboratório, métodos, purificação

\section{METHODS OF PURIFICATION OF WATER FOR LABORATORIES}

\begin{abstract}
Water is essential substance for the survival of living organisms, and occurs naturally on the planet in a composition that favors life. However, when it comes to water for laboratory procedures, neither natural water nor treated drinking water are adequate. For these applications, water needs to be purified for the removal of impurities, such


as microorganisms and their byproducts, organic and inorganic matter, ions and particles, all of which may interfere with laboratory procedures. To this end, physical, chemical and biological methods are used for water purification, such as distillation, filtration, micro- and ultrafiltration, reverse osmosis, deionization, electrodeionization, adsorption, and ultraviolet oxidation. All these methods are used to transform ordinary water in reagent water. For minimum quality standards to be achieved, such as ISO 3696 and CLSI GP40-A4-AMD, combination of two or more of these techniques is necessary, as well as proper handling and maintenance of purification equipment and systematic analysis of the reagent water, in a way to ensure water quality and suitability for the intended use. Thus, distillation and electrodialysis are little used in laboratories as distillation is time-consuming and electrodialysis shows low cost-benefit ratio. On the other hand, filtration, reverse osmosis, deionization, adsorption, and ultraviolet oxidation are widely used, usually in combination, as they are more effective, efficient, and easier to be performed.

KEYWORDS: laboratory, methods, purification, reagent water

\section{INTRODUÇÃO}

Monóxido de dihidrogênio, ou simplesmente água, de fórmula química $\mathrm{H}_{2} \mathrm{O}$, é uma molécula que, nas condições normais de temperatura e pressão, se apresenta como um líquido incolor, inodoro e insípido, que possui como pontos de solidificação e ebulição, respectivamente, $0^{\circ} \mathrm{C}$ e $99,974^{\circ} \mathrm{C}$ e peso molecular de $18.01528 \mathrm{~g} \cdot \mathrm{mol}^{-1}$. É, ainda, uma molécula polar, com pH 7 e considerada o solvente universal (EISENBERG; KAUZMANN, 2005; CHANG; GOLDSBY 2013; AZEVEDO et al., 2014; PANG, 2014).

$\mathrm{Na}$ Terra, a água ocorre naturalmente nos três estados físicos da matéria (sendo, inclusive, a única substância a apresentar tal característica) - líquido, como nos rios, mares e na chuva; sólido, como nas calotas polares, neve e granizo; e gasoso, como nas nuvens e gêiseres. Entretanto, na que ocorre naturalmente não estão presentes apenas dois átomos de hidrogênio ligados a um átomo de oxigênio - nela podem estar presentes metais, minerais, gases e microrganismos dos mais diversos (LOMOLINO et al., 2010; LYNDEN-BELL et al., 2010).

Tais fatos são fundamentais para a existência da vida como é conhecida - a água líquida à temperatura ambiente se torna disponível para os seres vivos, que podem aproveitá-la diretamente como meio de nutrição, habitat e higienização; as características da densidade da água permitem a ressurgência dos oceanos e a flutuabilidade dos icebergs. Além de tamanha importância para a viabilização da vida, a água é também de extrema importância para a facilitação da mesma, em especial no que tange aos humanos, que a utilizam para cozinhar, lavar, se deslocar por grandes distâncias, praticar esportes, lazer, produção de alimentos de origens animal e vegetal, pesquisas, entre outros (EISENBERG; KAUZMANN 2005; LYNDEN-BELL et al., 2010).

Entre seus inúmeros empregos pode ser citada sua utilização nos laboratórios. Nestes ambientes a água é de fundamental importância, sendo utilizada desde a higienização geral do ambiente até pesquisas e produção. Nestes dois últimos casos, onde podem ser citados o preparo de medicamentos, de reagentes e a limpeza de vidrarias, a água com as características físicas, químicas e biológicas como é encontrada naturalmente ou distribuída para o consumo humano não é indicada. Para tais tarefas é preciso utilizar uma água de grau reagente, 
purificando a água "comum", removendo microrganismos e seus compostos e fragmentos, cátions, ânions, gases e partículas. Para a remoção destes compostos são necessárias técnicas de purificação, tais como destilação, deionização, osmose reversa, filtração, ultrafiltração, oxidação ultravioleta, entre diversos outros. A eficiência e as técnicas necessárias dependem do uso que será dado à água reagente (MENDES et al., 2011; SOUZA et al., 2015).

Este trabalho de revisão bibliográfica contempla os principais métodos de purificação da água para uso laboratorial, sendo descritos cada um deles, o produto final e quais suas aplicações e limitações. Desta maneira, demonstra-se quais os métodos de purificação são recomendados para as diversas atividades laboratoriais. Para isso, utilizaram-se artigos científicos, normas reconhecidas internacionalmente, livros, manuais de empresas e artigos que tratassem sobre métodos de purificação da água, bem como de procedimentos que requerem água purificada e, para a introdução, aqueles que contemplem características da água e sua ocorrência natural.

Após, selecionou-se aqueles que mais se adequassem ao tema em questão. No caso das normas utilizadas, apesar de existirem dezenas, possivelmente centenas mundialmente respeitadas, foram selecionadas a "International Organization for Standardization" (ISO) por ser uma organização mundialmente reconhecida e o "Clinical and Laboratory Standards Institute" (CLSI) porque foi a única citada em todas as referências consultadas (quando não era a única), indicando sua grande influência e respeito por parte dos mais diversos órgãos. Uma vez analisadas as referências selecionadas, foram então transcritas as informações assimiladas e mais pertinentes.

Tal revisão é importante para que se tenham compilados, em um único documento, os principais métodos para purificação da água, bem como suas principais características, facilitando a escolha do mais indicado para cada atividade.

\section{DESENVOLVIMENTO}

$\mathrm{Na}$ água encanada podem estar presentes diversas substâncias, como cloro, flúor, cálcio, magnésio, sódio, cobre, selênio, potássio, microrganismos e pirogênios, entre diversos outros, bem como características como variações no pH, turbidez, condutividade elétrica, dependendo das condições naturais e do sistema de saneamento e distribuição. Desta forma, para que esta possa ser utilizada nas atividades realizadas nos mais variados tipos de laboratórios (por exemplo análises clínicas e análises físico-químicas) é necessário que uma ou mais dessas substâncias e características sejam ajustadas - alteradas, removidas ou tenham suas concentrações reduzidas (WHO, 2005; MENDES et al., 2011).

Para que se conheçam quais são as características ideais da água reagente para cada finalidade, organizações como a ISO e CLSI elaboram instruções classificando-a por classes ou tipos, onde cada característica apresenta ou não valores ideais máximos e/ou mínimos. Entre os principais parâmetros analisados estão: microrganismos, pirogênios, orgânicos (carbono orgânico total e absorbância), partículas (partículas em suspensão), coloides e íons (resistividade e condutividade). Para procedimentos específicos, como no uso farmacêutico, orientações específicas podem ser necessárias. Com relação à classificação da água reagente, a norma ISO 3696 classifica como classe 1,2 e 3, já a CLSI 
classifica como tipos 1, 2, 3 e CLRW (água para laboratório de análises clínicas) (ISO, 1997; BRASIL, 2005; CLSI, 2006; NABULSI; ABBADI 2014)

Várias substâncias e microrganismos podem causar interferências em procedimentos laboratoriais (THERMO SCIENTIFIC, 2013; ELGA PURELAB WATERGUIDE, 2005):

- Microrganismos e pirogênios - podem causar interferências em análises de material biológico e afetar o funcionamento de etapas do sistema de purificação onde bactérias podem eventualmente proliferar. Podem ser incluídos na lista, ainda, vírus e nucleases (SALTER et al., 2014).

- Materiais orgânicos (presença de carbono) - a presença de carbono na água interfere nas trocas iônicas e em análises que envolvam carbono, cromatografia, fluoroscopia, eletroforese e cultura de células e tecidos, bem como pode causar a corrosão de metais com os quais entrará em contato (EMD MILLIPORE, 2012).

- Partículas - normalmente com tamanho de 1 a $10 \mathrm{~m}$, podem tornar a água turva, causando problemas desde o funcionamento de instrumentos até análises, bem como entupimentos em outros equipamentos e processos de purificação da água (SHARMA, 1997).

- Colóides - normalmente com tamanho de 0,01 a $1 \mathrm{~m}$, não decantam por gravidade, permanecendo suspensos na água, podendo interferir em análises ao causar turbidez e atrapalhar no funcionamento de diversos sistemas de purificação, como troca iônica, osmose reversa e entupindo filtros (SHARMA, 1997).

- Íons - a presença de íons, como silicatos e cloretos, causa aumento na condutividade e redução na resistividade da água, afetando tanto análises de inorgânicos, como absorção atômica, cromatografia de íons e espectrometria de massas com plasma indutivamente acoplado, quanto de orgânicos, como o crescimento de células e tecidos, além de reduzir a vida útil de cartuchos no sistema de deionização (EMD MILLIPORE, 2012).

- $\mathrm{pH}$ - variações no $\mathrm{pH}$ podem afetar diversos tipos de análises, tanto de inorgânicos, como análises de $\mathrm{pH}$, quanto de orgânicos, como culturas de células e tecidos (U.S. PHARMACOPEIA, 2016).

De acordo com a classificação da norma ISO 3696:1987 (Quadro 1), a água de classe 3 é aceitável para a maioria dos trabalhos que envolvam química líquida (procedimentos manuais baseados na observação), bem como para o preparo de soluções reagentes, podendo ser utilizada para trabalhos analíticos comuns. A de classe 2 é indicada para análises sensíveis, como espectrometria de absorção atômica, e a de classe 1 é indicada para os mais rigorosos procedimentos analíticos, como cromatografia líquida (ISO, 1997). 
QUADRO 1. Classificação da água reagente conforme ISO 3696:1987

\begin{tabular}{|c|c|c|c|}
\hline Parâmetro & Classe 1 & Classe 2 & Classe 3 \\
\hline Condutividade $(\mu \mathrm{S} / \mathrm{cm})$ & $<0,1$ & $<1,0$ & $<5,0$ \\
\hline $\mathrm{pH}$ a $25^{\circ} \mathrm{C}$ & $\mathrm{NA}$ & $\mathrm{NA}$ & $5,0-7,0$ \\
\hline Matéria oxidável(conteúdo de $\left.\mathrm{O}_{2} \mathrm{mg} / \mathrm{L}\right)$ & $\mathrm{NA}$ & $\mathrm{NA}$ & $<0,04$ \\
\hline $\begin{array}{c}\text { Absorbância a } 254 \mathrm{~nm} \text { e } 1 \mathrm{~cm} \text { de } \\
\text { distância (unidades de absorbância) }\end{array}$ & $<0,001$ & $<0,01$ & $\mathrm{NA}$ \\
\hline $\begin{array}{c}\text { Resíduo após evaporação em } \\
\text { aquecimento a } 110^{\circ} \mathrm{C}(\mathrm{mg} / \mathrm{L})\end{array}$ & $\mathrm{NA}$ & $<1$ & $<2$ \\
\hline Sílica $(\mathrm{mg} / \mathrm{L})$ & $<0,01$ & $<0,02$ & $\mathrm{NA}$ \\
\hline
\end{tabular}

$\mu \mathrm{S} / \mathrm{cm}$ - microSiemens por centímetro

$\mathrm{mg} / \mathrm{L}$ - miligrama por litro

$\mathrm{nm}$ - nanômetro

NA - não se aplica

Fonte: Adaptado de International Organization for Standardization 1997.

De acordo com a classificação da CLSI GP40-A4-AMD dos tipos de água reagente (Quadro 2), a do tipo 3 é indicada para a limpeza de vidrarias, para a produção de água de maiores graus de pureza e preparo de culturas bacteriológicas; a do tipo 2 é indicada para processos onde a presença de bactérias é tolerada e a do tipo 1 é indicada para análises onde exige-se maior grau de precisão e exatidão, preparo de soluções padrão e tampão e procedimentos onde a presença de microrganismos deva ser a menor possível. A água CLWR (Clinical Laboratory Reagent Water, ou água reagente para laboratório clínico) é indicada principalmente para o uso farmacêutico e de análises clínicas (CLSI, 2006).

QUADRO 2. Classificação da água reagente conforme CLSI GP40GP40-AAMD

\begin{tabular}{|c|c|c|c|c|c|}
\hline Contaminante & $\begin{array}{c}\text { Parâmetro e } \\
\text { unidade }\end{array}$ & Tipo 3 & Tipo 2 & Tipo 1 & CLRW \\
\hline Íons & $\begin{array}{c}\text { Resistividade } \\
(\mathrm{M} / \mathrm{cm})\end{array}$ & $>0,05$ & $>10$ & $>18$ & $>10$ \\
\hline Orgânicos & $\begin{array}{c}\text { Carbono orgânico } \\
\text { total }(\mathrm{ppb})\end{array}$ & $<200$ & $<50$ & $<10$ & $<500$ \\
\hline Pirogênios & $(\mathrm{Eu} / \mathrm{mL})$ & $\mathrm{NA}$ & $\mathrm{NA}$ & $<0,03$ & $\mathrm{NA}$ \\
\hline Partículas & $\begin{array}{c}\text { Partículas }>0,2 \mu \mathrm{m} \\
\text { (unidades } / \mathrm{mL})\end{array}$ & $\mathrm{NA}$ & $\mathrm{NA}$ & $<1$ & $\begin{array}{c}\text { Filtraçã } \\
0 \text { a } \\
0,22 \\
\mu \mathrm{m}\end{array}$ \\
\hline Coloides & Sílica $(\mathrm{ppb})$ & $<1000$ & $<100$ & $<10$ & $\mathrm{NA}$ \\
\hline Bactérias & Bactéria (UFC/mL) & $<1000$ & $<100$ & $<1$ & $<10$ \\
\hline
\end{tabular}

$\mathrm{NA}$ - não se aplica

$\mathrm{M} / \mathrm{cm}$ - megaohms por centímetro

$\mathrm{Ppb}$ - partes por bilhão

$\mathrm{Eu} / \mathrm{mL}$ - unidades Elisa por milímetro

UFC - unidades formadoras de colônias por $\mathrm{mL}$

Fonte: Adaptado de Clinical Laboratory Standards Institute (2006). 
Além da atenção à utilização do método de purificação correto para cada atividade, é importante a constante análise das características finais da água submetida ao método de purificação em questão, a fim de se garantir a eficiência do método, bem como a correta instalação e manutenção do equipamento de purificação (KAWAl et al. 2004; CARTWRIGHT, 2006).

Entre os principais métodos utilizados na purificação de água para laboratórios estão a destilação, a filtração, a micro, ultra e nanofiltração, a osmose reversa, a deionização, a eletrodeionização, a adsorção e a oxidação ultravioleta, além de combinações entre estas técnicas (THERMO SCIENTIFIC, 2013; ELGA, 2005).

\section{Destilação}

Destilação é um processo que busca remover substâncias presentes num meio com base na diferença do ponto de ebulição entre elas. Para tanto, a água é aquecida até seu ponto de ebulição, o vapor resultante é direcionado para um recipiente, onde fica armazenado após a condensação, conforme Figura 1 - assim, gases dissolvidos que apresentem um ponto de ebulição maior do que o da água e partículas ficarão retidos no recipiente inicial, não sendo transportados com o vapor, da mesma forma que gases que apresentem ponto de ebulição inferior ao da água podem ser eliminados antes que a água atinja seu ponto de ebulição. Entre os métodos de purificação, é o que apresenta a maior abrangência com relação aos tipos de impurezas removidas. Por não ser um sistema sob demanda, a água reagente deve ser preparada e armazenada, o que aumenta as chances de contaminação, além do fato de que apenas cerca de $5 \%$ de toda a água utilizada no processo é convertida em água reagente (ELGA, 2005; VIJYA et al., 2013).

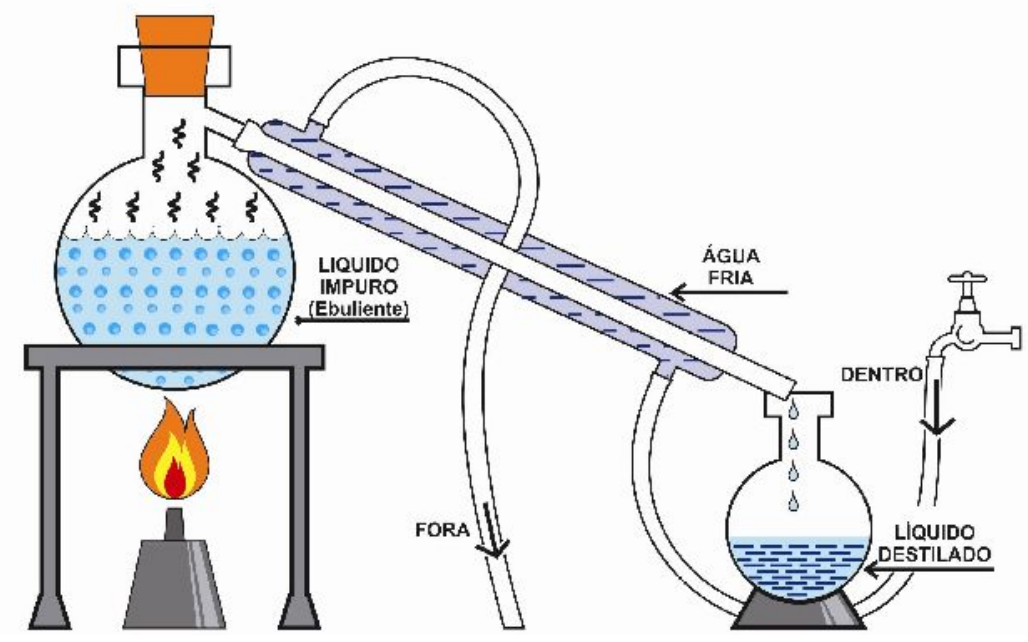

FIGURA 1. Esquematização do processo de destilação da água. Fonte: Adaptado de Azevedo et al., (2014)

A utilização de energia solar, embora não seja a predominante, tem se mostrado uma opção viável para o processo de destilação da água de poços ou do mar em substituição à energia advinda de hidroelétricas. O processo de destilação 
de água utilizando energia solar tem atraído o setor industrial com alta demanda desse tipo de água, mas também produzem água para o consumo humano e podem se destinar aos laboratórios inclusive (JESUS, 2015).

Cada vez mais fica notória a finitude dos recursos hídricos no Brasil e no mundo e, sendo assim, todas as atividades que consomem grande volume de água despertam a atenção dos pesquisadores e suscitam investigações quanto ao reuso dos seus efluentes. Nesse contexto estão inclusos os destiladores de água que consumem muitos litros de água potável a cada litro de água destilada produzida e geram efluentes com características que permitem a utilização no próprio laboratório onde são produzidos reduzindo gastos e tornando mais sustentável o processo (MARISCO et al., 2017).

\section{Filtração}

Filtração é um procedimento simples de remoção física de partículas presentes na água. Neste método a água passa por algum material poroso de forma que as partículas fiquem retidas, conforme explicitado na Figura 2. Costuma ser utilizada em diversos pontos do sistema de purificação de água de maneira a proteger e prolongar a vida útil dos equipamentos seguintes, porém não remove material dissolvido (VIJYA et al., 2013).

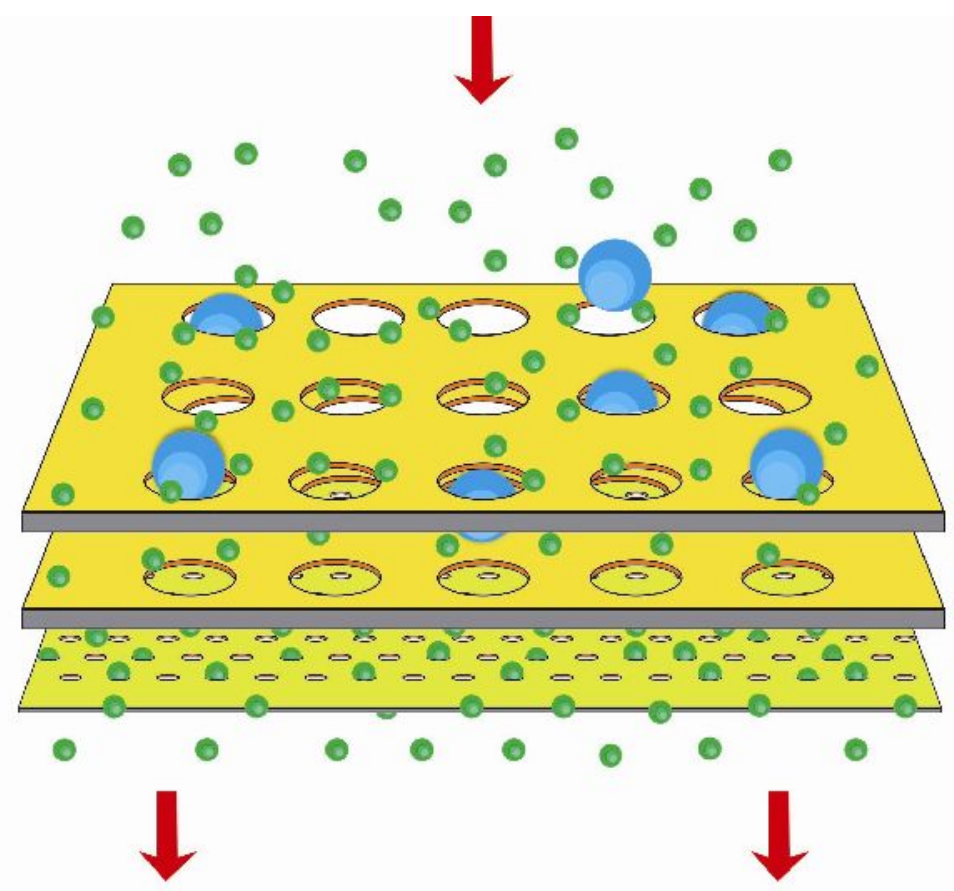

FIGURA 2. llustração do processo de filtração. Fonte: Adaptado de Li et al, 2014.

\section{Microfiltração, Ultrafiltração e Nanofiltração}

Microfiltração, ultrafiltração e nanofiltração, assim como a filtração, são procedimentos de remoção física de partículas, porém agem no final do sistema de purificação, onde um filtro retém partículas superiores a determinado tamanho, sendo que na ultrafiltração e nanofiltração são removidos ainda os sais dissolvidos. 
No caso da microfiltração são retidas partículas com tamanho entre 0,1 e 10 m (e.g. partículas suspensas, bactérias, algas, turbidez), sendo 0,22 m um tamanho bastante comum entre os filtros comercializados. Na ultrafiltração as partículas retidas têm entre 0,1 e $0,01 \mathrm{~m}$ (e.g. vírus, coloides, macromoléculas), enquanto a nanofiltração retém partículas com tamanho entre 0,01 e 0,001 m(e.g. compostos orgânicos e íons bivalentes) (ELGA, 2005; VIJYA et al., 2013).

\section{Osmose Reversa}

Osmose é um processo no qual um solvente passa por uma membra semipermeável, na direção do meio de menor pressão osmótica (com menor concentração de soluto, portanto hipertônica) para o meio de maior pressão osmótica (com maior concentração de soluto, hipertônica) de modo a equalizar a concentração, tendendo à isotonia. Tal processo ocorre de forma natural e sem a necessidade de pressões externas. Isso ocorre porque, com as diferenças de concentração, ocorre uma diferença nas pressões de cada lado No caso da osmose reversa ocorre o processo inverso, no qual pressão externa é utilizada de modo a forçar o fluxo do solvente no sentido do meio de maior pressão osmótica para o de menor pressão osmótica (HOWE et al., 2016).

A osmose reversa visa a remoção de substâncias como compostos orgânicos e inorgânicos, bactérias e pirogênios, com tamanho inferior a 0,001 m (e.g. íons univalentes), portanto posterior aos processos de micro, ultra e nanofiltração, mas não é eficiente na remoção de gases dissolvidos. Para tanto, a água é forçada, sob pressão, contra uma membrana semipermeável, por onde a água passa e as substâncias em questão ficam retidas, conforme figura 3 (ELGA, 2005; VIJYA et al., 2013; HOWE et al., 2016).

Tal método apresenta considerável geração de rejeitos, uma vez que há a retenção de compostos. Entretanto, considerando que a água que chega ao equipamento de osmose reversa no laboratório já passou por outros processos de purificação, estudos indicam que esta água pode ser reaproveitada, seja para a limpeza externa, seja com sua diluição para eventuais usos mais nobres (FARIA et al., 2016; RIBEIRO et al., 2016).

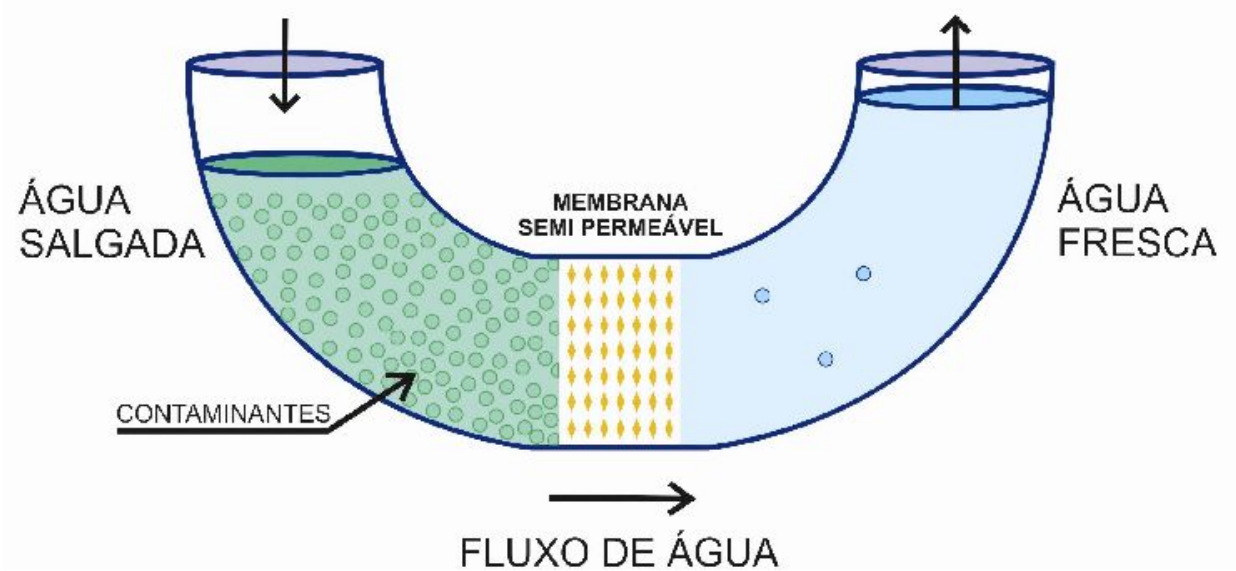

FIGURA 3. Representação do funcionamento da osmose reversa.

Fonte: Adaptado de Puretec, 2018. 


\section{Deionização, Desmineralização ou Troca lônica}

Deionização, desmineralização ou troca iônica é um processo que visa a remoção de íons pela passagem da água por pequenas esferas de resina eletricamente carregadas, o que permite a troca seletiva de íons dissolvidos - são trocados íons de hidrogênio $\left(\mathrm{H}^{+}\right)$pelos contaminantes catiônicos presentes, bem como íons de hidroxila $\left(\mathrm{OH}^{-}\right)$pelos contaminantes aniônicos presentes, de acordo com o ilustrado na Figura 4. Após determinado tempo ou vazão o conjunto precisa ser trocado, ou as esferas regeneradas com aplicação de ácidos e bases, pois as esferas de resina perdem seus íons de hidrogênio e hidroxila, ficando em seu lugar os íons removidos. Entre as limitações deste processo estão a remoção de partículas, matéria orgânica, bactérias e pirogênios (MERK MILLIPORE, 2018; VIJYA et al., 2013).
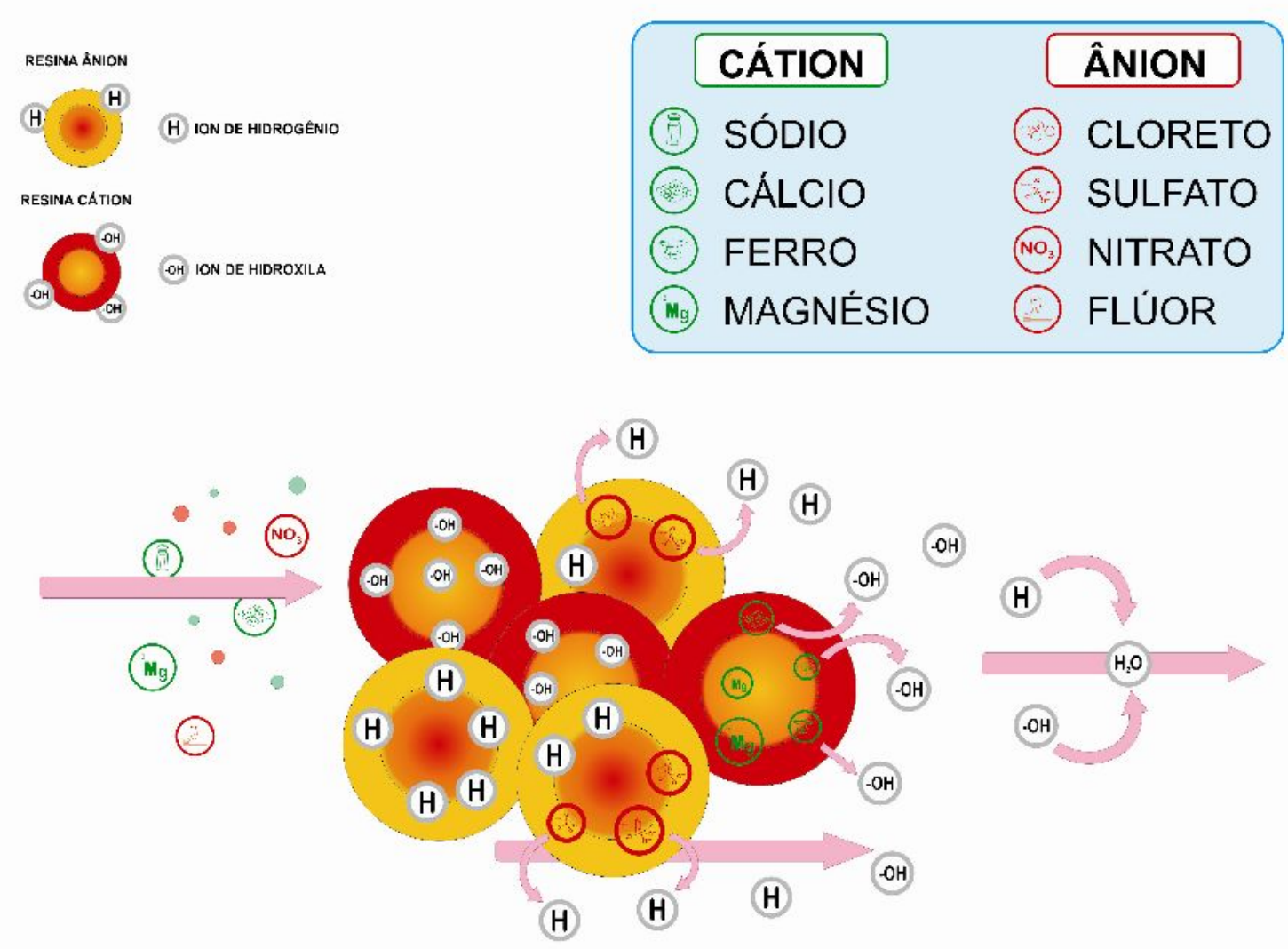

FIGURA 4. Ilustração das trocas iônicas realizadas na deionização. Fonte: Adaptado de US Water Systems, 2018

\section{Eletrodeionização}

Eletrodeionização é um processo de remoção de íons presentes na água que combina a deionização à eletrodiálise - correntes elétricas atraem os íons através de membranas seletivas (folhas com propriedades semelhantes às esferas de resina da troca iônica), conforme Figura 5. Possui a vantagem, sobre a deionização, de que as membranas seletivas são continuamente regeneradas. A eletrodiálise, apenas, é um processo mais utilizado para a remoção de sais de água salobra a fim de torná-la 
potável - para o uso em laboratório, tal método se mostra menos eficiente e mais custoso, além de exigir manutenções mais frequentes e pessoal especializado (LEE et al., 2013; VIJYA et al., 2013).

\section{PROCESSO DE ELETRODEIONIZAÇÃO}

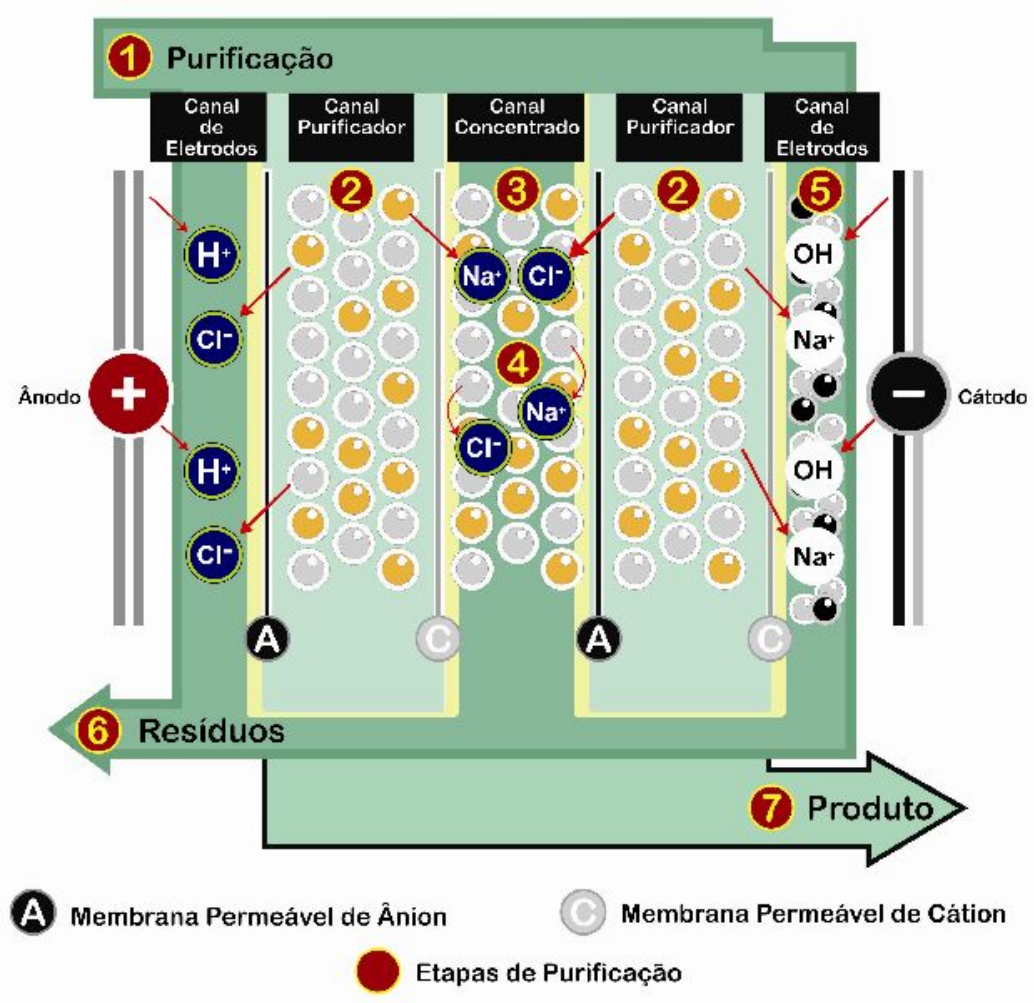

FIGURA 5. Representação do processo de eletrodeionização.

Fonte: Adaptado de Merck Millipore.

\section{Adsorção}

Adsorção é um processo de remoção de cloro e substâncias orgânicas porquimisorção e fisissorção, respectivamente, baseado na passagem da água por carvão ativado ou carvão sinterizado. Na adsorção, moléculas de líquido ou gás se ligam à superfície de um sólido ou líquido, conforme exemplificado na figura 6 . Normalmente este procedimento é realizado antes dos sistemas de osmose reversa e deionização, uma vez que elementos destes sistemas são sensíveis ao cloro e podem ter sua vida útil reduzida. Tal método não é capaz de remover íons e 
partículas (VIJYA et al., 2013; INTERNATIONAL UNION OF PURE AND APPLIED CHEMISTRY, 2016).

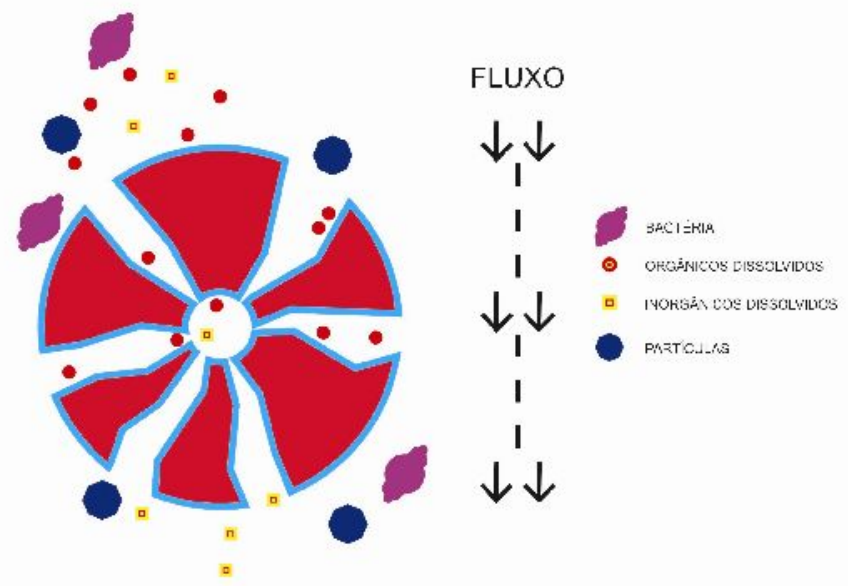

FIGURA 6. Ilustração do funcionamento do processo de adsorção. Fonte: Adaptado de Merck Millipore, 2018.

\section{Oxidação Ultravioleta}

Oxidação ultravioleta é um processo que visa inviabilizar microrganismos presentes na água por meio da radiação ultravioleta com frequência de $254 \mathrm{~nm}$. É também utilizada, nas frequências de 185 e 254 nm, para oxidar moléculas orgânicas presentes. Por não ser um processo de remoção, mas de inativação, este método deve ser utilizado antes dos processos de remoção de partículas da água. A figura 7 ilustra este processo. (VIJYA et al., 2013; KRÖCKEL; SCHMIDT, 2014).

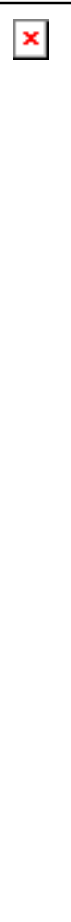

FIGURA 7. Esquematização do processo de oxidação ultravioleta. Fonte: Adaptado de Trojan UV, 2018. 
O quadro 3 relaciona os diversos métodos de purificação com sua eficácia na remoção das diversas impurezas.

QUADRO 3. Relação método de purificação/remoção de impureza

\begin{tabular}{|c|c|c|c|c|c|c|}
\hline & $\begin{array}{c}\text { Íon } \\
\mathrm{s}\end{array}$ & $\begin{array}{c}\text { Gases } \\
\text { dissolvid } \\
\text { os }\end{array}$ & $\begin{array}{c}\text { Orgânico } \\
\mathrm{s}\end{array}$ & $\begin{array}{c}\text { Partícula } \\
\mathrm{s}\end{array}$ & $\begin{array}{c}\text { Bactéria } \\
\mathrm{s}\end{array}$ & $\begin{array}{c}\text { Pirogênio } \\
\text { s/endotoxi } \\
\text { nas }\end{array}$ \\
\hline Destilação & + & \pm & \pm & + & + & + \\
\hline Filtração & - & - & - & + & + & - \\
\hline Ultrafiltração & - & - & \pm & + & + & + \\
\hline Osmose Reversa & \pm & - & \pm & + & + & + \\
\hline Deionização & + & + & - & - & - & - \\
\hline Eletrodeionização & + & + & - & - & - & - \\
\hline Adsorção & - & \pm & \pm & - & - & - \\
\hline Oxidação UV & - & - & $+/ \pm$ & - & $+/ \pm$ & - \\
\hline
\end{tabular}

${ }^{*}+\rightarrow$ remoção total ou alta $\pm \rightarrow$ remoção parcial $\rightarrow \rightarrow$ remoção nula ou baixa Fonte: Adaptado de APHA 2012 e Thermo Scientific 2013.

Podem (e devem) ser feitas, ainda, combinações dos métodos acima a fim de que um sistema supra as carências do anterior, como é normalmente feito por empresas que fabricam sistemas de purificação da água - Elix e Milli-Q, da Merck Millipore, e Barnstead Gen Purex CAD Plus, da Thermo Scientific, são alguns exemplos (THERMO SCIENTIFIC, 2013).

Milli-Q, por exemplo, é um equipamento que combina sistemas de filtração, osmose reversa, adsorção, deionização, oxidação ultravioleta e ultrafiltração para entregar uma água ultrapura Tipo 1 ou Classe 1 (respectivamente CLSI e ISO). Elix, por sua vez, é um equipamento que combina a filtração, a adsorção, a osmose reversa e, opcionalmente, a oxidação UV, que produz água pura Tipo/Classe 2 indicada para o preparo de reagentes e tampões, meios de cultura e também como fonte de alimentação para o Milli-Q e equipamentos diversos. Barnstead Gen Purex CAD Plus é outro sistema de ultrapurificação, que combina diversos métodos para oferecer água Tipo/Classe 1 indicada para culturas de células e tecidos, PCR, sequenciamento de DNA, eletroforese, cromatografia líquida de alta performance, cromatografia gasosa, cromatografia gasosa acoplado à espectrometria de massa, espectrometria de massa com plasma indutivamente acoplado, absorção atômica, medições de carbono orgânico total, IC, entre outras (NABULSI; ABBADI, 2014; ELGA, 2005).

\section{CONSIDERAÇÕES FINAIS}

A água de correta classificação e purificada pelos métodos apropriados aplicada à finalidade correta é essencial para a garantia dos resultados daquilo que será analisado nos laboratórios. Para sua obtenção é necessário que a água encanada passe por sistemas de filtragem mecânica e de adsorção, a fim de que sejam removidas as partículas maiores e parte dos gases dissolvidos.

Para o preparo de meios de cultura, reagentes químicos, tampões e alimentação para sistemas de ultrapurificação, recomenda-se a água de tipo 2 
(CLSI). Para tanto, o sistema é alimentado com água reagente tipo 3 seguida de métodos de micro, ultra e nanofiltração, bem como osmose reversa, a fim de que sejam removidas as partículas menores, podendo também haver outra etapa de adsorção para que a remoção dos gases dissolvidos seja mais eficiente.

Para análises de absorção atômica, carbono orgânico total, cromatografia gasosa, cromatografia iônica, cromatografia líquida de alta performance, cultura de células e tecidos, eletroforese, espectrometria de massa, espectrometria de plasma indutivamente acoplado, reação em cadeia de polimerase, uma vez que trabalham com traços de elementos, células e DNA, requer-se a água de tipo 1 (CLSI). Para tanto, exige-se que o sistema seja alimentado por água reagente tipo 2; a água será tratada, adicionalmente, por radiação ultravioleta, podendo haver redundância nos demais sistemas de purificação a fim de se garantir maior eficiência do método.

A utilização de água reagente de maior pureza para a realização de ensaios que requeiram uma de menor pureza é permitida, ao passo que a situação contrária não pode ocorrer, não sendo aceita a utilização de água reagente de menor pureza do que aquela exigida pelo método.

\section{REFERÊNCIAS BIBLIOGRÁFICAS}

AMERICAN PUBLIC HEALTH ASSOCIATION (APHA), AMERICAN WATER WORKS ASSOCIATION (AWWA), WATER ENVIRONMENT FEDERATION (WEF). Standard Methods for the Examination of Water and Wastewater.22 ${ }^{\mathrm{a}} \mathrm{ed}$. Washington (DC); 2012.

AZEVEDO, J.S.; FREQUI, M.; TRSIC, M. Curso de química para engenharia. Barueri: Manole. 2014.

BRASIL. Ministério da Saúde (BR). Agência Nacional de Vigilância Sanitária (ANVISA). Dispõe sobre regulamentação técnica para funcionamento de laboratórios clínicos. Resolução da Diretoria Colegiada, RDC nํ302. Brasília; 2005.

CARTWRIGHT, P. Process water treatment - challenges and solutions. Chemical Engineering Journal, v. 113, n. 3, p. 50-56, 2006.

CHANG, R.; GOLDSBY, K.A. Química. Porto Alegre : AMGH. 2013.

CLINICAL LABORATORY STANDARDS INSTITUTE. Preparation and testing of reagent water in the clinical laboratory. GP40-A4-AMD.4를 ed. Wayne, PA. 2006.

EISENBERG, D.; KAUZMANN, W. The structure and properties of water. Oxford: Oxford University Press. 2005.

ELGA. Pure lab water guide: An essential overview of lab water purification applications, monitoring and standards. High Wycombe: ELGA LabWater/VWS, UK: 2005.

EMD MILLIPORE. The importance of water quality in HPLC and LC-MS. AAPS SCPDG. 2012. 
FARIA, P. G. S.; NAGALLI, A.; FREIRE, F. B.; RIELLA, M. C. Reaproveitamento do concentrado gerado por sistema de tratamento de água por osmose reversa em uma clínica de hemodiálise. Revista Engenharia Sanitária e Ambiental, v.21, n.2, p.329-336, 2016, Disponível em: < http://www.scielo.br/pdf/esa/v21n2/18094457-esa-21-02-00329.pdf>. DOI: 10.1590/S1413-41522016122029. Acesso em 07 nov 2018.

HOWE, K. J.; HAND, D.W.; CRITTENDEN, J.C.; TRUSSELL, R.R. | TCHOBANOGLOUS, G. Princípios de tratamento de água. São Paulo: Cengage, 2016.

INTERNATIONAL ORGANIZATION FOR STANDARDIZATION.ISO 3696:1987 "water for analytical laboratory use - specification and test methods". Switzerland; ISO; 1997.

INTERNATIONAL UNION OF PURE AND APPLIED CHEMISTRY. Disponível em: http://old.iupac.org/reports/2001/colloid_2001/manual_of_s_and_t/node16.html. Acesso em: 13 mar 2016.

JESUS,G. O.; FREITAS, J. J. S. O.; SILVA, R. J. S.; FORTE, L. G.; MATTEDI, S.S.; FIUZA, R. P. Destilação de Água por Energia Solar. Cadernos de Prospectivas, Salvador, v. 8, n. 3, p. 469-477, jul./set. 2015. Disponível em $<$ http://dx.doi.org/10.9771/S.CPROSP.2015.008.052>. doi:10.9771/S.CPROSP.2015.008.052

KAWAI, M.; YAMAGISHI, J.; YAMAGUCHI, N.; TANI, K.; NASU, M. Bacterial population dynamics and community structure in a pharmaceutical manufacturing water supply system determined by real-time PCR and PCR-denaturing gradient gel electrophoresis. Journal of Applied Microbiology, v. 97, n. 6, p. 1123-1131, 2004. Disponível em: <https://doi.org/10.1111/j.1365-2672.2004.02396.x>.doi 10.1111/j.1365-2672.2004.02396.x

KRÖCKEL, L.; SCHMIDT, M. A. Extinction properties of ultrapure water down to deep ultraviolet wavelengths. Optical Materiais Express, v. 4, n. 9. p. 1932-1942, 2014. Disponível em: <http://dx.doi.org/10.1364/OME.4.001932>. doi. 10.1364/OME.4.001932

LEE, H. J.; SONG, J. H.; MOON, S. H. Comparison of electrodialysis reversal (EDR) and electrodeionization reversal (EDIR) for water softening. Desalination, v. 313, p. 43-49, 2013.

LI, S.; LIAO, G.; LIU, Z.;PAN, Y.; WU, Q.; WENG, Y.; ZHANG, X.; YANG, Z.; TSUI, O.K.C. Enhanced water flux in vertically aligned carbon nanotube arrays and polyethersulfone composite membranes. Journal of Materials Chemistry A, v.2, p.12171-12176, 2014. Disponível em: <http://dx.doi.org/10.1039/C4TA02119C>. doi: 10.1039/C4TA02119C 
LOMOLINO, M. V.; RIDDLE, B.R.; WHITTAKER, R.J.; BROWN, J.H. Biogeography. 4르. ed. Massachusetts: Sinauer Associates; 2010.

LYNDEN-BELL, R. M.; MORRIS, S. C.; BARROW, J. D.; FINNEY, J L. Harper C. Water and life: the unique properties of H2O. Florida: CRC Press; 2010.

MARISCO, L. V.; FERNANDES, V. C.; CAVAGNI, M. V.; FERNANDES, C. L; FERNANDES, J. C. Reúso de Efluentes Provenientes de Aparelhos Destiladores. Revista de Ciências Exatas Aplicadas e Tecnológicas da Universidade de Passo Fundo, v.6, n. 1, p.37-47, 2014. Disponível em: <http://dx.doi.org/10.5335/ciatec.v6i1.3488>. doi: 10.5335/ciatec.v6i1.3488

MENDES, M. A.; FAGUNDES, C. C.; PORTO, C. C.; BENTO, L. C.; COSTA, T. G. R.; SANTOS, R. A., SUMITA, N. M. A importância da qualidade da água reagente no laboratório clínico. Jornal Brasileiro de Patologia e Medicina Laboratorial, v. 47, n. 3, p. 217-223, 2011. Disponível em: <http://dx.doi.org/10.1590/S1676-

24442011000300004. doi: 10.1590/S1676-24442011000300004

MERCK MILLIPORE. Water in the laboratory. Disponível em: http://www.merckmillipore.com/BR/pt/water-purification/learningcenters/tutorial/purification-techniques/M42b.qB.QHEAAAFAVVZkiQz9,nav. Acesso em: 17 abr 2018.

NABULSI, R.; ALABBADI, M. A. Review of the impact of water quality on reliable laboratory testing and correlation with purification techniques. Laboratory Medicine, v. 45, n. 4, p. 159-165, 2014. Disponível em:

<https://doi.org/10.1309/LMLXNDOWNRJJ6U7X>. doi:

10.1309/LMLXNDOWNRJJ6U7X

PANG, X. F. Water: molecular structure and properties. Singapore: World Scientific; 2014.

PURETEC. What is reverse osmosis? Disponível em:

https://puretecwater.com/reverse-osmosis/what-is-reverse-osmosis. Acesso em: 17 abr 2018.

RIBEIRO, L.; SANCHES-PAGLIARUSSI, M.; RIBEIRO, J. Reutilização da sobra de água permeada e de rejeito de uma central de tratamento de água por osmose reversa de uma unidade de hemodiálise hospitalar. Brazilian Journal of

Biosystems Engineering, v. 10., n. 3, p. 259-272, 2016. Disponível em: <http://dx.doi.org/10.18011/bioeng2016v10n3p259-272>

SALTER, S. J.; COX, M. J.; TUREK, E. M.; CALUS, S. T.; COOKSON, W. O.; MOFFATT, M. F., TURNER, P.; PARKHILL, J.; LOMAN, N. J.; WALKER, A. W. Reagent and laboratory contamination can critically impact sequence-based microbiome analyses. BMC Biology, v. 12, p. 02-12, 2014. Disponível em: <http://dx.doi.org/10.1186/s12915-014-0087-z>.doi: 10.1186/s12915-014-0087-z 
SHARMA, B. K. Industrial chemistry including chemical engineering. $16^{a}$ ed. Meerut: GOEL Publishing House, 1997.

SOUZA, R. Q.; GONÇALVES, C. R.; IKEDA, T.I.; CRUZ, A.S.; GRAZIANO, K.U. O impacto do último enxágue na citotoxicidade de produtos críticos passíveis de processamento. Revista da Escola de Enfermagem da USP, v. 49, p. 87-92 , 2015. Disponível em:< http://dx.doi.org/10.1590/S0080-623420150000700013>.doi: $10.1590 /$ S0080-623420150000700013

THERMO SCIENTIFIC.Thermo Scientific waterbook. Thermo Fisher Scientific. 2013.

TROJAN UV.UV-oxidation Process - Environmental Contaminant Treatment. Disponível em: http://www.trojanuv.com/applications/ect. Acesso em: 17 abr 2018.

U.S. PHARMACOPEIA. Disponível em:

http://www.pharmacopeia.cn/v29240/usp29nf24s0c1231.html. Acesso em: 25 jul 2016.

US WATER SYSTEMS. How deionization works. Disponível em: https://www.uswatersystems.com/commercial/commercial-systems/deionizationsystems-di/di-cartridge-systems. Acesso em: 17 abr 2018.

VIJYA, P.; KRUNALI, T.; ROHIT, M.; MESHRAM, D. B. A review on various techniques and parameters signifying purity of water. Innovare Journal of Food Sciences, v. 1 n. 1, p. 8-14, 2013.

WORLD HEALTH ORGANIZATION. Nutrients in drinking water 2005.Water, Sanitation and Health Protection and the Human Environment. Geneva; WHO; 2005. 